\title{
LA PALABRA POÉTICA Y LA (RE)INVENCIÓN DE AMÉRICA
}

\author{
Diana Araújo Pereira \\ (Universidade Federal da Integração \\ Latino-americana - UNILA)
}

Si se borra de nuestra circunstancia la poesía, se les quita la tierra firme a nuestras plantas. Lo bueno de América está en que, fuera de ser un continente racional, es eso y algo más. Es un Nuevo Mundo poético.

(Germán Arciniegas)

\section{De metáforas y nuevos mundos}

La conquista de América es, antes que nada, un viaje de las palabras; un proceso histórico y linguístico que empieza con la necesidad de "metaforización" de las lenguas ibéricas ante la inaudita realidad americana. Las palabras, en la creación del "Nuevo Mundo", participan del proceso de acercamiento y adaptación a esta tan distinta realidad, a la vez que amplían su potencial de acción, jugando un rol fundamental en el movimiento de hibridación que se extiende del lenguaje a los cuerpos e imaginarios.

Aquí la metáfora se entiende, por tanto, en un sentido filosófico que va mucho más allá de su uso como mero recurso estético-formal para la 
construcción de un poema, o un adorno necesario al lenguaje literario. Ella actúa, en este choque de mundos y culturas, como una base motriz para el pensamiento y, más específicamente, para la construcción de una nueva subjetividad colectiva que de cuenta de la era que se inaugura y, por ende, del imaginario colectivo. Tanto en las relaciones individuales (del hombre en busca de sí mismo), como en las relaciones sociales, la metáfora ejerce un papel fundamental de interacción. Según el filósofo Ortega y Gasset (1952, p. 390): “[...] No sólo la necesitamos para hacer, mediante un nombre, comprensible a los demás nuestro pensamiento, sino que la necesitamos inevitablemente para pensar nosotros mismos ciertos objetos difíciles. Además de ser un medio de expresión, es la metáfora un medio esencial de intelección". Y en otro ensayo lo complementa (1932, p. 907): “[...] la metáfora es probablemente la potencia más fértil que el hombre posee. Su eficiencia llega a tocar los confines de la taumaturgia y parece un trebejo de creación que Dios se dejó olvidado dentro de una de sus criaturas al tiempo de formarla [...]. Sólo la metáfora nos facilita la evasión y crea entre las cosas reales arrecifes imaginarios, florecimiento de islas ingrávidas".

El proceso de "invención de América”, así nominado por el historiador mexicano Edmundo O’ Gorman en su célebre libro de 1958, tiene su inicio en el siglo XV con la llegada de Cristóbal Colón al continente. Se inventa América desde la mirada europea, cargada de mitos y símbolos medievales, además de sus propias referencias culturales, pero al mismo tiempo cargada de una fuerte dosis de saturación social y económica. La Europa de los siglos XV y XVI necesita expandirse mercantil y espiritualmente en busca de territorios geográficos que suplan, también, sus necesidades de otro orden, más político y estratégico. Algunos historiadores señalan este proceso como el inicio de la modernidad y la "globalización". Los diversos productos vegetales, las llamadas especierías o especias, daban el sabor y el olor a una época destinada al expansionismo y al cultivo de la técnica; a la sobreposición del hombre y su imaginación por encima del legado teocéntrico todavía vigente.

La llegada de Europa a América deflagra no un "encuentro de culturas" sino un largo y doloroso proceso de hibridación cultural que tiene sus inicios en las primeras frases de Colón en su diario: "Puestos en tierra vieron árboles muy verdes, y aguas muchas y frutas de diversas maneras." La exuberancia y el frescor vegetal y de la naturaleza en general se suman a la desnudez indígena para luego convertirse el hallazgo en la tabula rasa cultural y espiritual del "Nuevo Mundo", destinado a la pluma y escritura europeas. 
Las metáforas construidas a través de los relatos, cartas y crónicas de la conquista crean el discurso que va a determinar el nacimiento - la condena - de América como "Nuevo Mundo" (PAZ, 1989). El proceso posterior, sobre todo durante el siglo republicano, será de reajustes y negociaciones entre estas mismas imágenes que a pesar de mantenerse como base del nuevo momento histórico también tienen que adaptarse a él. El llamado "darwinismo social" - que cundía en los discursos de las élites europeas y latinoamericanas (por poner un ejemplo, pensemos en el libro del escritor boliviano Alcides Arguedas, Pueblo Enfermo, 1909) - no es más que una actualización de los debates de la Junta de Valladolid entre Bartolomé de las Casas y Juan Ginés de Sepúlveda que allá en 1550/1551 discutían sobre la humanidad de los indios. La misma metáfora del ser del Nuevo Mundo como tabula rasa relaciona su habitante originario a la "infancia" de la humanidad (Las Casas) o a su "animalidad" (Sepúlveda). Posteriormente cobra nuevos matices cada vez más "científicos” y con ello se legitima en el imaginario evolucionista y cientificista que impone orden y progreso a la recién independizada América que, de hecho, no alcanza la tan necesaria independencia de las viejas metáforas y con ello de todo un orden social y ontológico heredados de la colonia.

\begin{abstract}
El inagotable debate, nunca concluido, que aparece desde el encuentro va a condicionar toda la acción de la Corona en las Indias, va a provocar los más apasionados y eruditos pronunciamientos, va a alcanzar su culminación en la polémica trágica de Las Casas con Sepúlveda y va a condicionar la comprensión de la historia y la mentalidad hispanoamericana de manera indeleble (USLAR PIETRI, 1996, p. 197).
\end{abstract}

Estos procesos dejan sus huellas en el imaginario colectivo y en la memoria histórica del continente y alcanzan los siglos XX y XXI a través de una serie de metáforas recicladas o "metáforas zombis", como les llama el ensayista Emmánuel Lizcano (2006), tornando perdurables y legítimos todos los intentos de revisión histórica, cultural, social y/o económica que de vez en cuando emergen en el continente.

La fuerza de las ideologías se asienta principalmente en este tipo de metáforas, que más que 'muertas' yo prefiero llamar 'zombis', pues se trata de auténticos muertos vivientes que nos hacen ver por sus ojos, sentir por sus sensaciones, idear con sus ideas, imaginar con sus imágenes. La alienación que caracteriza al discurso ideológico está precisamente en esa ocupación del imaginario por un imaginario ajeno, en el uso de metáforas que imponen una perspectiva que no se muestra como tal sino como expresión de las cosas mismas, que así resultan inalterables (LIZCANO, 2006, p. 65). 
Por tanto, el "Nuevo Mundo" se inventa -se forja- como una construcción imaginaria, ficcional, en la cual participaron la violencia de los cuerpos, de las armas y de las letras a través de la actuación de los cronistas, soldados y sacerdotes: hombres de la palabra escrita, servidores de la autoridad letrada. En este sentido, podemos pensar con Martin Lienhard (autor del emblemático libro La voz y su huella, de 1992) en la imposición letrada como una de las violencias más perdurables en la memoria colectiva, por lo simbólico que involucra en el proceso de conquista y colonización y por favorecer el endurecimiento de lo que antes era mudable oralidad.

Para comprender la urdimbre humana y geográfica que significó la “invención de América", la poesía y la historia se enriquecen mutuamente, intercambiando herramientas para la reflexión sobre el pasado, el presente y el futuro del continente. La literatura y las artes en general, pero sobre todo la poesía, por su libertad imaginativa y linguística - de forma y contenido - permiten acceder al pasado, volver la vista hacia atrás, recrear experiencias que se mantienen vivas en el gran mosaico de la memoria colectiva. Es más: darles otras interpretaciones, relativizando la linealidad del tiempo, abriéndolo a nuevas posibilidades. A propósito se pregunta Eduardo Galeano (1990, p. 13): "Acender consciências, revelar a realidade: pode a literatura reivindicar melhor função nestes tempos e nestas terras nossas?” Y enseguida completa (GALEANO, 1990, p. 15): "Uma literatura nascida do processo de crise e de mudança e metida a fundo no risco e na aventura de seu tempo pode ajudar muito bem a criar os símbolos da realidade nova e talvez ilumine, se o talento não faltar e tampouco a coragem, os sinais do caminho. Não é inútil cantar a beleza e a dor de ter nascido na América."

La palabra poesía, que viene del griego poiesis, alcanza su sentido pleno de acción al promover nuevos territorios de reflexión y crítica. Para contrarrestar el discurso histórico oficial y hegemónico varios escritores, desde la lírica y la narrativa contemporáneas, se proponen llenar los vacíos dejados por dicho discurso y para ello echan mano de nuevas metáforas (vivas) o de la inversión de metáforas antiguas. Según Lizcano (2006, p. 68) "metáforas vivas [son] aquellas que establecen una conexión insospechada entre dos significados hasta entonces desvinculados, aquellas que, abruptamente, ofrecen una nueva perspectiva sobre algo familiar y nos hacen verlo con nuevos ojos [...]. Metáforas vivas lo son, por antonomasia, las metáforas poéticas."

Como consecuencia, "reescribir" la historia latinoamericana se convierte en un objetivo y un reto para toda una pléyade de escritores que encuentran en la palabra poética dicho espacio propicio al trabajo de la 
memoria - un territorio simbólico suficientemente libre y democrático, desde donde pensar o re-pensar nuestros procesos constitutivos y deflagradores. La poesía como campo de experimentación y de batalla o, como nos instiga a pensar Octavio Paz (1998, pp. 13-14), como "operación capaz de cambiar el mundo [...]; Oración, letanía, epifanía, presencia. Exorcismo, conjuro, magia. Sublimación, compensación, condensación del inconsciente. Expresión histórica de razas, naciones, clases", en cuyo contexto "el poema no es una forma literaria sino el lugar de encuentro entre la poesía y el hombre.”

Principalmente a partir de los movimientos vanguardistas, en las primeras décadas del siglo pasado, la necesidad de refundar América Latina se insinúa en una rica producción literaria comprometida con la realidad más inmediata aunque comprometida también con las idiosincrasias históricas que definen esta misma realidad - una escritura claramente implicada en enlazar vida y arte, crónica íntima y crónica social, individualidad y colectividad.

La ya antigua utopía europea, que desembarca con el bagaje de la conquista, será puesta en jaque por la intelectualidad nativa, de la misma forma como la supremacía del pensamiento europeo y la visión etnocéntrica que siempre determinaron nuestros límites reflexivos. Reescribir la historia y la poética latinoamericanas, intervenir con gestos simbólicos en el imaginario que nos enmarca, se ha convertido en una preocupación fundamental y en un proyecto definitorio para este grupo de intelectuales que ha decidido arriesgarse en busca de un pensamiento y un arte propios. En dicho proceso, el lenguaje amplía su poder de intervención en la realidad y zambulle en las aguas de nuestra memoria, con el fin de rescatar mitos y dilemas, conflictos y esperanzas.

Comprometidos con todo este contexto, varios escritores configuran una verdadera hermandad poética que alimenta el continente, intensificando relaciones que se sobreponen a límites geográficos y/o temporales, reafirmando la unión que desde el siglo XV se convierte en una de las bases principales de Nuestra América: la relación entre las letras y la política. Sobre eso escribe el cubano Alejo Carpentier, allá en los 6o (1999, p. 51): "Este oficio de hombre, he tratado de desempeñarlo lo mejor posible. En eso estoy, y en eso seguiré, en el seno de una revolución que me hizo encontrarme a mí mismo en el contexto de un pueblo. Para mí terminaron los tiempos de la soledad. Empezaron los tiempos de la solidaridad". Estos escritores, con mayor o menor conciencia, se involucran en el ambicioso proyecto colectivo de refundar y redescubrir el tiempo presente en el cual se inscriben, como una contemporaneidad en constante diálogo con la memoria del pasado y la "memoria del futuro" 
forjada desde la conquista por las utopías suscitadas tanto en el imaginario europeo como en el latinoamericano.

A lo largo del siglo XX la revolución, esta palabra tan adorada como vilipendiada por la historia y el pensamiento occidentales, pasa de proceso político-social, de acción real y concreta de transformación radical de la sociedad, a una clase de fuerza propulsora y mítica que invade el imaginario colectivo y ahí se establece, naturalizando el deseo de transformación social y asociándolo sobre todo a ámbitos como el poético, el artístico o el religioso. Es así como surgen las transformaciones en el pensamiento, en el lenguaje estético y, por otro lado, fenómenos religiosos como la Teología de la Liberación (en los 6o) o, más recientemente, el influjo metafórico que enarbola la wiphala (la bandera-emblema del Tawantinsuyo) en cuantas manifestaciones político-culturales haya en la comarca andina.

Como fruto de todo este largo proceso de "invención de América" que todavía no ha llegado a su término - nos inventamos una riqueza artística y reflexiva que se forma sobre la fragmentación y el desplazamiento identitarios, otorgándolea la América Latina contemporánea instrumentos que le confieren mayor movilidad y creatividad a sus prácticas culturales. Y que reafirman la esperanza como una base más profunda, capaz de sobrevivir a las intemperies de los procesos históricos. Es sobre esta base que surgen las diversas y tan variadas manifestaciones poéticas y artísticas que buscan redibujar el sujeto y el entorno latinoamericanos, convirtiendo los trazos del hibridismo en fuente de riqueza identitaria y cultural.

\section{2. (Re)inventar América en el siglo XX}

Después de todo, resulta ya natural afirmar la pervivencia de los discursos e imágenes que cundieron durante la conquista y colonización (ante el asombro de la nueva realidad que se imponía, a través de la pluma de sacerdotes, soldados y escribanos dedicados a plasmar y darle materialidad a una realidad que les sobrecogía) y que nos llegan con vitalidad renovada en pleno siglo XXI. Si pensamos nuestro tiempo como nos propone el filósofo Giorgio Agamben (2009, p. 72) según el cual el ser contemporáneo a su propia época "é também aquele que, dividindo e interpolando o tempo, está à altura de transformá-lo e de colocá-lo em relação com os outros tempos, de nele ler de modo inédito a história", entonces nos vamos sintiendo aún más cómodos al reconocer las ficciones que nos habitan y las metáforas que nos piensan y determinan nuestra visión de la historia (LIZCANO, 2006). 
A modo de ejemplo, por poner un caso concreto y 1. Establecer un paralelismo actual entre la ya aludida relación - tan propia de la historia de América Latina - entre las letras y la política y 2. Señalar la vigencia del imaginario de la conquista en la contemporaneidad, comentemos muy brevemente la significación colectiva de algunas de las metáforas que metaboliza el Presidente de Bolivia, Evo Morales (2006). Su propia persona -performance estética y proyectos políticos- son un claro ejemplo de la capacidad de permanencia de toda una memoria ligada a la conquista y colonización que, no sin tensiones, sobrevive en el orden social e imaginario actuales no solo de su región como de toda América Latina.

Un poco antes, en el Perú, el ex-presidente Alejandro Toledo (20012006) elige como escenario simbólico y político para su toma de posesión la ciudadela de Machu Picchu. Su esposa le acompaña con un discurso en quechua que enarbola las banderas de la justicia para los pobres de la tierra y anuncia nuevos tiempos para el pueblo del Tawantinsuyo. Cuando nada más subir al poder, en el 2006, en el sitio arqueológico de Tihuanaco (equivalente boliviano de la ciudadela peruana), Evo Morales refuerza el ideario andino e invierte la experiencia de Toledo (quien primero había hecho su ceremonia "oficial" en Lima, para luego hacerla en versión "simbólica" en Machu Picchu, mientras que Evo Morales lo hace primero en Tihuanaco), intenta tal vez mostrar que su experiencia político-administrativa sería más radical que la de su homólogo peruano, muy pronto tildado de neoliberal.

Para bien o para mal, como uso publicitario o efectivamente político, la toma de posesión de un Presidente de la República con todos los atuendos simbólicos que introducen elementos del pasado originario de América a los ritos políticos del Estado Nacional, relacionándolos, por tanto, a otros erigidos en el proceso de modernización del continente, es algo que por sí mismo llama la atención. En este contexto, queda clara la legitimidad que le confiere a un mandatario político del siglo XXI relacionarse con las demandas históricas ancladas en los siglos XV y XVI aunque tan ampliamente actualizadas por el sistema de explotación capitalista y neoliberal que se viene imponiendo en los últimos siglos.

Ya en el primer discurso de Morales en La Paz se nota la continuidad de toda una lucha político-cultural que relaciona las distintas formas de resistencia colonial a los actuales movimientos sociales: "Para recordar a nuestros antepasados por su intermedio señor presidente del Congreso Nacional, pido un minuto de silencio para Manco Inca, Túpac Katari, Túpac Amaru, Bartolina Sisa, Zárate Villca, Atihuaiqui Tumpa, Andrés Ibáñez, Che Guevara, Marcelo Quiroga Santa Cruz, Luis Espinal, a muchos de mis hermanos caídos, cocaleros de la zona del trópico de Cochabamba, por 
los hermanos caídos en la defensa de la dignidad del pueblo alteño, de los mineros, de miles, de millones de seres humanos que han caído en toda América, por ellos, presidente, pido un minuto de silencio".

El recorrido de los nombres citados por el Presidente crea un puente entre los siglos XVI y XXI al articular temporalidades distintas bajo el homenaje común a los "hermanos caídos", los que dieron su vida por el ideal de la lucha colectiva. Resulta imposible no pensar en lo mítico que se entrecruza con lo político al observar sus propuestas administrativas o el traje indígena que lleva a las ceremonias oficiales en las que participa (sin concesiones a la obviedad de la vestimenta "occidental"), o incluso al ver en cada manifestación colectiva por las calles la ascensión de la ancestral wiphala, la bandera originaria, de las manos de su pueblo, como ya se ha señalado.

En este contexto, la poesía y las artes van a ser un importante escenario donde dichas metáforas, imágenes y relatos históricos van a negociar su vigencia a través de continuidades y rupturas que se enlazan al ámbito sociopolítico; funcionan como puntos de arranque a todo un imaginario colectivo que, a su vez, imprime movimiento a los procesos simbólicos y culturales con clara incidencia político-social. Por tanto, la creación artística promueve posibilidades de intervención de parte de este hombre latinoamericano dispuesto a "renombrar" las metáforas del Nuevo Mundo como lo que son: metáforas, ficciones, de esa manera liberando el tiempo presente de su peso muerto de ideologías concretadas bajo el poder de las letras y las armas.

El arte propicia la circulación simbólica y la comunicación entre los elementos que integran nuestra realidad socio-histórica; por otro lado se rebela contra esa misma realidad, sea linguística, metafórica o incluso político-social, a través de la posibilidad mágica y revolucionaria de la poesía. Las artes juegan, por tanto, un papel fundamental en la representación, ruptura y/o mantenimiento de la memoria histórica del continente.

\section{3. "Cristóbal Colón inventa el Nuevo Mundo", de Eliseo Diego}

El cubano Eliseo Diego (1920-1994) es un poeta de la delicadeza, de la suavidad de las cosas cotidianas, de las anécdotas sencillas. Pero a la vez es una de sus prácticas el meterse en la piel de personajes literarios o históricos para luego peregrinar con más libertad por otros tiempos y geografías. Desde diálogos imaginarios o desde perspectivas ajenas, Eliseo Diego logra inmiscuirse en territorios temporales y poéticos para 
luego hacerlos suyos, generando nuevas experiencias a sus lectores que, tomados de la mano del poeta, se sienten sumergir en nuevas versiones de antiguos relatos.

Un caso muy especial es el del poema que aquí se va a comentar, publicado en el libro Los días de tu vida (1977). Este libro, por cierto, toca especialmente el tema de la historia como una urdimbre hecha de hilos de tiempo; en verdad, tiempos plurales: míticos, simbólicos, ficcionales, sumados y mezclados a los tiempos de la historia, cuyo resultado es una ambivalencia fluida entre lo individual y lo colectivo, entre la subjetividad íntima y la versión pública de los hechos. En el poema "Testamento", que cierra el libro, Eliseo Diego nos declara su intención de tocar "todo el tiempo", es decir, de ampliarlo lo más posible: "decido hacer mi testamento./ Es /éste: les dejo /el tiempo, todo el tiempo."

En el caso del poema "Cristóbal Colón inventa el Nuevo Mundo", el poeta se inserta en la problemática versión del descubrimiento de América, otorgándole a Cristóbal Colón la posibilidad de decirnos más de lo que ha podido a través de su diario o de la escritura de la época. Si llevamos en cuenta que leemos a Colón de la mano del fray Bartolomé de las Casas, quien compiló su diario, nada más natural que seguir al poeta en su ejercicio de diálogo histórico que es, también, un ejercicio discursivo y metapoético, donde el poema se vuelve "vía de acceso al tiempo puro, inmersión en las aguas originales de la existencia. La poesía no es nada más sino tiempo, ritmo perpetuamente creador" (PAZ, 1998, p. 26).

Por otra parte, hay que llamar la atención para el hecho de que este poema es el primero de un proceso que en las décadas siguientes encontrará nuevos cómplices en la literatura hispanoamericana: la reescritura de nuevas versiones de la conquista a través del intento de varios escritores de asomarse al interior de uno de sus protagonistas: Cristóbal Colón. Le anticipan los historiadores Edmundo O'Gorman y Germán Arciniegas, pero la osadía literaria de Los Perros del Paraíso (1987), del argentino Abel Posse o Vigilia del Almirante (1992), del paraguayo Augusto Roa Bastos tardarán unos años en llegar.

De hecho, el mismo Colón es un personaje histórico que tiene mucho de ficcional ya que los datos concretos de su biografía siguen siendo un misterio a solucionar. Su vida es un relato colmado de vacíos y sus escritos son, sin lugar a dudas, documentos fundacionales de nuestra literatura. Las imágenes creadas por Colón y ratificadas por Las Casas se sumergieron en nuestra memoria colectiva y se hicieron basilares de nuestra imaginación. Como afirma el historiador Germán Arciniegas (in COBO BORDA, 1993, p. 425): "Hablando de la literatura universal, sólo hay una de la cual sabemos la fecha exacta en que comenzó a escribirse: la 
literatura hispanoamericana. El día 12 de octubre de 1492, cierto marino de palabras pintorescas y expresivas pergeñó en su cuaderno de bitácora la primera descripción del Nuevo Mundo. [ ] Así nació la poesía con el descubrimiento".

Ya el escritor Arturo Uslar Pietri (1996, p. 205) parece no sólo estar de acuerdo con lo anterior sino ampliarlo: la importancia de los primeros registros del "descubrimiento", más allá de la escrita literaria, encauzan el cambio revolucionario del pensamiento occidental que se va a generar a consecuencia: "No ha habido documento más influyente en la evolución de la mentalidad europea que aquella carta del Almirante, que es el acta de nacimiento de una nueva era." Veamos el poema:

\section{I}

Toda la noche, toda,

Cristóbal Colón oye pasar los pájaros.

Viniendo del abismo, sin fin, a ráfagas,

miles y miles de pájaros. Sobre los mástiles,

atravesando, acribillando las tinieblas, allá,

el ruido de las alas de los pájaros.

Viniendo del vacío, del abismo,

el ruido, el trueno de la vida siendo,

la orquesta entera de los pájaros.

Pálido como la llama del farol, inmóvil,

Cristóbal Colón oye tronar la vida, pasar los pájaros.

Las imágenes de la primera parte del poema de Eliseo Diego recuperan el temor del abismo, las incertidumbres de un viaje geográfico que es, también, el viaje europeo del Medioevo al Renacimiento. En el fondo la esperanza, "la orquesta entera de los pájaros" que salen del "vacío", del "abismo" y de las "tinieblas".

II

Cristóbal Colón ha visto una luz donde no hay nada.

(El Almirante, no el advenedizo de Triana.)

Esa luz arde en algún sitio seco.

Tan seco, sin duda, como el sitio en que se posó la paloma.

Es luz de algún fuego encendido por la mano de un hombre.

Porque el fuego qué es sino la inteligencia del hombre.

Cristóbal Colón lo buscó toda su vida, esto es lo cierto.

Toda su vida de pobreza, toda su vida.

Fuego de cocinar pescado, puede que fuego de abrigo.

Fuego para la más modesta de las ceremonias.

De tan pequeño que es, no puede ser otra cosa, cómo va a serlo.

Porque Cristóbal Colón lo buscó toda su vida, toda.

Por eso ahora solloza solo en la cubierta

mientras el último de los pájaros se hunde vibrando en la memoria. 
Sí, el último de los pájaros

- uno con la primera

luz del alba.

La segunda parte del poema comienza con un verso que es una afirmación: "Cristóbal Colón ha visto una luz donde no hay nada". (Hay que advertir el dato curioso de que el poeta propone otra versión para el hecho de que ha sido Rodrigo de Triana quien ha visto por primera vez la tierra americana). La palabra luz se vuelve el elemento que encadena los dos ámbitos principales del viaje: la luz como iluminación y sabiduría, y la luz del fuego, de la tierra seca, de la supervivencia. Esta segunda estrofa se inicia y termina con la luz buscada y luego encontrada, la luz del alba o del inicio de una nueva era o de un nuevo mundo.

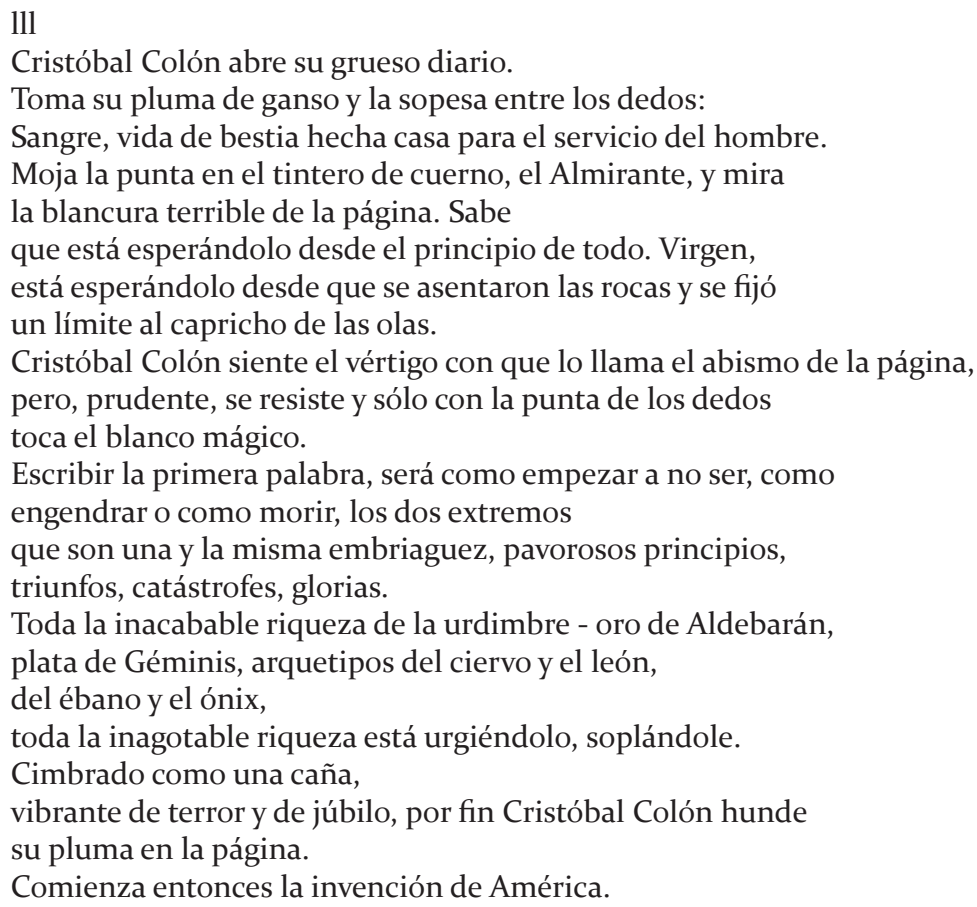

La tercera y última parte del poema empieza con la imagen que servirá de hilo conductor a la idea principal y se hará aún más clara al final: la de una invención del continente que es necesariamente una invención escrita. La palabra sangre se mezcla a la palabra tinta, elementos responsables por la escritura en este nuevo mundo entendido por los actores europeos de la conquista como una "página en blanco", y nos deja la imagen subliminal de la violencia que tal escritura involucraba, sea de orden física, concreta 
(sangre) o espiritual, simbólica (tinta). El vacío del desconocimiento de la primera parte resurge en el mismo vacío de "la blancura terrible de la página” y finalmente nos remite a la tabula rasa - metáfora que indicaba la forma con que los europeos vieron el continente.

El vértigo que siente el Almirante ante la posibilidad buscada aunque temida del parto de este nuevo mundo y de un tiempo también nuevo se traduce en la tensión que se establece entre vida y muerte, entre fin e inicio, entre "triunfos, catástrofes, glorias". Y es vibrando "de terror y de júbilo" que el Almirante actualiza el imaginario mítico europeo que le acompaña ("oro de Aldebarán, / plata de Géminis, arquetipos del ciervo y el león, / del ébano y el ónix") en esta mirada confusa y violenta que le imprime a la nueva tierra inventada, llenándola de mitos, símbolos y utopías que la hacen más palatable a un gusto ajeno, el europeo, occidental, premoderno: "[...] la visión de lo maravilloso percibido como real dio el paso definitivo a lo real percibido como maravilloso" (AINSA, 2006, p. 202).

El Almirante que nos presenta el poeta es el ser que se siente elegido por un Dios cristiano, quien carga consigo el desafío de crear sobre la página en blanco; un blanco mágico que se impone sobre la realidad cultural, religiosa, histórica y social de un continente ya ampliamente cultivado y habitado por grupos diversos, constituidos en sociedades distintas, con sus propias prácticas sociales, simbólicas y económicas. Y que, sin embargo, son sometidos a una nominación única y homogeneizante, los "indios" en una sola "América".

La reafirmación del protagonismo del Almirante sólo es comprensible si se le toma en sentido metonímico, como representante del grupo más amplio de los "conquistadores", ya que Colón no se da cuenta del hallazgo de las nuevas tierras y tampoco las ve bautizadas como América. Recordemos que el Almirante se mueve con claro objetivo de encontrar el pasaje a las Indias Orientales, en el escenario de disputa entre las Coronas Portuguesa y Española por dominar el Atlántico y que, para más inri, muere creyendo haber encontrado - si ya no la ruta al Oriente - el Paraíso Terrenal. Por lo tanto, la afirmación "Colón descubrió América” es risible (RESTALL, 2006) en varios sentidos y concretiza la ironía histórica de que Colón haya muerto sin reconocer el Nuevo Mundo, mientras haya sido Américo Vespuccio el responsable de su nombramiento, justo por haber comprendido la importancia y el significado geográfico del novedoso territorio.

Es así que de las ironías, violencias y violaciones varias de tal proceso surge el Nuevo Mundo inventado por la mirada y la pluma europeas para luego convertirse en la posibilidad de recreación de aquel viejo mundo gastado y sumido en injusticias y enfermedades de muchos órdenes. Un 
nuevo mundo inventado a la medida para convertirse, por tanto, en la utopía europea. Sin embargo, este proyecto europeizante jamás ha salido a la perfección, y después de tantos siglos de luchas internas, sociales y simbólicas, históricas e imaginarias, hemos alcanzado una suerte de negociación. Desde tierras americanas ha salido otra versión de la utopía primera. Una versión propia, o como dice el filósofo Martín Hopenhayn (1995, p. 280-281): una "utopía que reduzca mezclando, y que luego potencie mezclando. Utopía que recombine la escasez del presente para sugerir la plenitud del futuro. Utopía que es imposibilidad fáctica; pero también necesidad cultural, reto político."

A modo de conclusión, podemos llegar a pensar -con García Canclini (2000)- que la utopía se ha convertido en la verdadera identidad de América; y esta misma identidad utópica se fortalece a medida que pierde corporeidad, que se desterritorializa América Latina; a medida que vuelve a ser metáfora. Pero ahora ya una metáfora engendrada dentro del continente, aunque posteriormente reconocida y reivindicada por la Europa conflictiva de la contemporaneidad como el espacio intermedio ideal, grávido de futuro, como nos dice, entre otros, el historiador Serge Gruzinski: [América Latina] "encierra en su pasado algo con lo cual afrontar mejor el mundo posmoderno en el que nosotros nos estamos hundiendo" (GRUZINSKI, 1994, p. 215).

Enmarcada por tantas ironías, América vuelve a ser la utopía europea, la posibilidad de salvación (incluso económica) en un tiempo de "barbarie", marcado por el inicio de un nuevo siglo cargado de nuevas crisis y temblores. Ahora le toca a América Latina dejar ya sus dolores genésicos de "nuevo mundo" y enseñar cómo se sobrevive al caos de la fragmentación y la pérdida de identidades seguras. Un continente que ha mantenido en el imaginario colectivo el lema de que la crisis no supone el colapso sino el desafío a la creatividad.

Los tiempos barajados se levantan y se entremezclan a fin de instaurar fisuras y fricciones que nos hagan volver a tocar las construcciones mentales que todavía nos someten a las jerarquías de poder a nivel global. Poder que es político pero también cultural. América Latina tiene un fuerte e importante capital simbólico que hacer circular, y para ello el arte y la literatura se vuelven territorios fundamentales de conocimiento mutuo y autoconocimiento, además del escenario ideal -por democrático y diverso- desde donde fomentar la larga y delicada negociación entre la recuperación y mantenimiento de aspectos del pasado -simbólicos y/o socioeconómicos- y el proceso de modernización que desde los viajes del siglo XV hasta la contemporaneidad intenta convertir el mundo en una misma "aldea global". 
En este continente la poesía se erige en constante diálogo con la conciencia histórica, política y social que nos define. Y las relaciones que fomenta entre tales instancias son siempre insumisiones a las imágenes de progreso y modernidad que nos llegaron como la única opción posible. El territorio poético, el más rebelde, busca las palabras propias y alternativas, las que asociándose a los sistemas culturales y sociales enlazan utopía y realidad a lo largo de tantos siglos, intentando (re)descubrir un mundo nuevo a medida de lo finalmente somos.

\section{REFERENCIAS BIBLIOGRÁFICAS}

AGAMBEN, Giorgio. O que é o Contemporâneo? E outros ensaios. Trad. Vinícius Nicastro Honesko. Chapecó: Argos, 2009.

AINSA, Fernando. Del Topos al Logos. Propuestas de Geopoética. Madrid: Iberoamericana, 2006.

CARPENTIER, Alejo. Visión de América. Buenos Aires: Losada, 1999.

COBO BORDA, Juan Gustavo. América Ladina. Germán Arciniegas. México: FCE, 1993.

DIEGO, Eliseo. Entre la dicha y la tiniebla. Antología poética 1949-1985. México: FCE, 1986.

FUENTES, Carlos. Tiempos y espacios. Madrid: FCE, 1998.

GALEANO, Eduardo. A descoberta da América (que ainda não houve). Trad. Eric Nepomuceno. Porto Alegre: Editora da Universidade/UFRGS, 1990.

GARCÍA CANCLINI, Néstor. Culturas Híbridas. Trad. Heloísa P. Cintrão e Ana Regina Lessa. SP: EDUSP, 2000.

GRUZINSKI, Serge. La guerra de las imágenes. México: FCE, 1994.

HOPENHAYN, Martín. Ni apocalípticos ni integrados. Aventuras de la Modernidad en América Latina. Santiago de Chile: FCE, 1995.

LIZCANO, Emmánuel. Metáforas que nos piensan. Sobre ciencia, democracia y otras poderosas ficciones. Ediciones Bajo Cero/Traficantes de Sueños, 2006.

O’ GORMAN, Edmundo. A Invenção da América. Trad. de Ana Maria M. Correa e Manoel Lelo Bellotto. SP: UNESP, 1992.

ORTEGA Y GASSET, José. Obras. Madrid: Espasa Calpe, 1932. . Obras completas. Madrid, Revista de Occidente, 1952.

PAZ, Octavio. El arco y la lira. México: FCE, 1998. 
PAZ, Octavio. Puertas al Campo. Barcelona: Seix Barral, 1989.

RESTALL, Matthew. Sete Mitos da Conquista Espanhola. Tradução: Cristiana de Assis Serra. RJ: Civilização Brasileira, 2006.

SUBIRATS, Eduardo. El Continente vacío. La conquista del Nuevo Mundo y la conciencia moderna. Madrid: Anaya \& Mario Muchnik, 1994.

USLAR PIETRI, Arturo. La invención de América Mestiza. México: FCE, 1996. 